\title{
Using Tracing Method for Calculation and Allocation of Reactive Power Cost
}

\author{
Seyed Mohammad Hossein Nabavi ${ }^{1}$, Somayeh Hajforoosh ${ }^{2}$, Sajad Hajforosh ${ }^{3}$, Nazanin \\ Alsadat Hosseinipoor ${ }^{4}$ \\ 1,2,3,4 Islamic Azad University, Tabriz Branch, Tabriz, Iran
}

\begin{abstract}
Conventional methods of determining and allocating of reactive power costs which are based on power factor do not provide an accurate method to consumers reactive power pricing. While support for ensuring proper and continuous reactive power is needed to generate sufficient incentives to generate reactive power. To motivate participates, it is needed to create an economic structure of reactive power. In this paper, a method for determining the cost of reactive power is presented considering direct and indirect costs in generating and transmission. The developed tracing method for allocating reactive power cost is introduced. Simulation results in the IEEE 30-bus test system are considered to test and validate the proposed method. The methodologies, results and discussion presented in this paper show that the presented method is practical and has reasonable speed for determination and allocating reactive power cost.
\end{abstract}

Keywords:

Reactive power, tracing method, opportunity cost.

\section{INTRODUCTION}

Conventional reactive power pricing methods are based on power factor. These methods are not suitable for the restructured power systems. Because in these systems the costs of each reactive power support services must be paid separately. In addition, current tariffs only consider local costs and calculate the reactive power consumption respect variables which can not judge the full customers usage [1-3]. Development of reactive power pricing service causes to nodal pricing theory definition [4-6]. More research work based on the nodal pricing has been presented in [7]. This method is sensitive to operating conditions and system constraints. Also, its computing time is considerable and due to nonlinearly its convergence is not acceptable.

Obtained capital from a pricing point for the overall cost of coverage is not enough and therefore additional pricing options are needed [2].

In this paper, a generalized method for allocation of reactive power cost is presented. By applying this method, calculation of the cost of generating and transferring and the allocation of costs between different users should be considered.

Generalized tracking method is based on actual costs of production conducted in reactive power. This method is a practical, fast and usable in large scale power systems. In addition, this method is useful in markets based and restructured environments.

\section{DETERMINE THE COST OF REACTIVE POWER}

Determination the cost of reactive power can be divided in two main parts: generation and transmission.

To calculate the opportunity cost of the generator, using the capacity curve generator, consider a point of reference for the determination of operational changes can reduce reactive power in exchange for real in the actual operation point to a reference point operation is required.

The reference point can be calculated using the system load flow results, regardless of voltage limits. Therefore, the reactive power cost is equivalent with the benefit of generators, which cannot produce active power. This cost is calculated as follows:

$$
O C R_{P}(\$)=\left(E_{P} * \Delta P * \Delta T-O C\right) /(K V A r h)
$$

(1)

$$
\text { where } O C R_{P}(\$) \text { is the reactive power opportunity cost, }{ }^{E_{p}} \text { is }
$$
the marginal cost of active power, $\Delta \mathrm{P}$ is the reduced active power, $\Delta \mathrm{T}$ is the duration of active power reducing, $O C$ is the operation costs, during the active power is reducing, and KVArh is the reactive power generation during the time [8].

Transmission system has an important role in reactive power transferring is the power systems. Equipment such as transformers, overheads lines, underground cables, reactive power compensation devices such as shunt and/or series capacitor banks, reactors (shunt and/or series), static VAR compensators are used in transmission systems.

In this paper, the costs of equipment such as transformers with tap changing capability and capacitor banks with switcher are considered and calculated.

\section{TRACKING AND COST ALLOCATION OF REACTIVE POWER}

Tracking consumption of each consumer can be calculated using the main laws establishing such as Ohm's Law and the Kirchhoff's law.

This algorithm starts using the obtained information solving the load flow. Then, the zone of each generator in the network is considered. In general, a zone of each generator is a graph that includes a generator, loads and the transmission lines, which are connected to the generators. 
In order to tracking the reactive power, it should be considering the various reactive power sources such generators, transmission lines and series and parallel compensation instruments exist. Some network elements as sources of reactive power transfer act and thus have own domain. In this study, all transport network elements are considered as branches. For branches which have two or more zones, proportional share method is used for calculating contributions of the each zone.

In each branch, reactive power contribution is calculated using proportional based method. Zones participations are obtained using the following equations, as shown in Fig. 1.

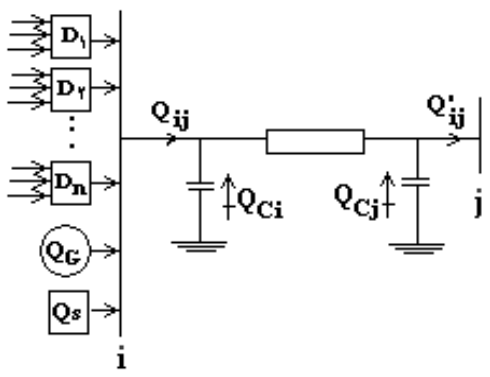

(a)

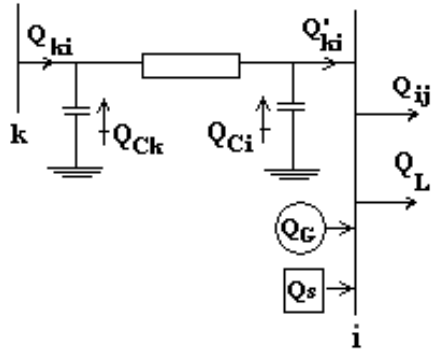

(b)

Fig. 1. The zone of participated (a) resource, (b) loads

$Q_{i j}=Q_{D 1}^{\prime}+Q_{D 2}^{\prime}+\ldots .+Q_{D n}^{\prime}+Q_{G}^{\prime}+Q_{S}^{\prime}$

$Q_{i j}^{\prime}=Q_{D 1}^{\prime \prime}+Q_{D 2}^{\prime \prime}+\ldots .+Q_{D n}^{\prime \prime}+Q_{G}^{\prime \prime}+Q_{s}^{\prime \prime}$

$Q_{D K}^{\prime}=Q_{D k} \times C_{i j}^{\prime}$

$Q_{D K}^{\prime \prime}=Q_{D k}^{\prime} \times C_{i j}^{\prime \prime}$

$Q_{G}^{\prime}=Q_{G} \times C_{i j}^{\prime}$

$Q_{G}^{\prime \prime}=Q_{G}^{\prime} \times C_{i j}^{\prime \prime}$

$C_{i j}^{\prime}=\frac{Q_{i j}}{\left(Q_{D 1}+Q_{D 2}+\ldots+Q_{D n}+Q_{G}+Q_{S}\right)}$

$C_{i j}^{\prime \prime}=\frac{Q_{i j}^{\prime}-Q_{c j}}{Q_{i j}+Q_{c i}}$

$Q_{s}^{\prime}=Q_{s} \times C_{i j}^{\prime}$

$Q_{s}^{\prime \prime}=\left(Q_{s}^{\prime}+Q_{c i}\right) \times C_{i j}^{\prime \prime}+Q_{c j}$

$C_{k i}^{\prime \prime}=\frac{Q_{k i}^{\prime}}{\sum_{k} Q_{k i}^{\prime}+Q_{G}+Q_{S}}$

$Q_{L_{k i}^{\prime \prime}}^{\prime \prime}=Q_{L} \times C_{k i}^{\prime \prime}$
$Z_{1}=\frac{Q_{k i}^{\prime}-Q_{c i}}{Q_{k i}^{\prime}}$

$Z_{2}=Z_{1} \times Q_{L_{k i}}^{\prime \prime}$

$Z_{3}=Z_{2} \times \frac{\left(Q_{k i}^{\prime}-Q_{c i}\right)}{\left(Q_{k i}+Q_{c k}\right)}$

$Q_{L_{k i}}^{\prime}=Z_{3} \times \frac{Q_{k i}}{\left(Q_{k i}+Q_{c k}\right)}$

The loads contributions in the loss of reactive power can be calculated using the proportional based method, as following:

$\Delta Q_{D K}=Q_{D K}^{\prime}-Q_{D K}^{\prime \prime}$

$\Delta Q_{L_{k i}}=Z_{2 k i}-Z_{3_{k i}}$

$C_{l_{k i}}=\frac{\Delta Q_{l_{k i}}}{\sum_{l} \Delta Q_{l_{k i}}} \quad, \quad l=1,2, \ldots, L$

$\Delta Q_{D K_{l}}=\Delta Q_{D K} \times C_{l_{k i}}$

\section{SIMULATION RESULTS}

The proposed method for determination and allocation of the reactive power is implemented on the IEEE 30-bus test system as shown in Fig. 2. The above algorithm is a general algorithm, which can be applied to the larger size of power systems. In this system, there are 30 buses, 40 transmission lines, six generators, two capacitor banks and 21 load points.

The investment cost of generators, using Eq.1 and Eq.3, are obtained that values are in Table 1. In addition, investment cost of capacitor banks is obtained from Eq.7 which is presented in Table 2.

The opportunity cost is calculated using Eq. 1. The obtained results for the opportunity cost of generators are presented in Table 3.

Table 1: Investment cost of generators reactive power

\begin{tabular}{|c|c|c|c|}
\hline \multirow{2}{*}{ Bus No. } & \multicolumn{3}{|c|}{ Annual investment cost of generator } \\
\cline { 2 - 4 } & $\$ / \mathrm{MW}$ & \$MVA & \$/MVAr \\
\hline 1 & $5 \times 106$ & 5157 & 1610 \\
\hline 2 & $3 \times 106$ & 7734 & 2415 \\
\hline 5 & $2 \times 106$ & 8839 & 2760 \\
\hline 8 & $3 \times 106$ & 8281 & 2898 \\
\hline 11 & $2 \times 106$ & 10313 & 3220 \\
\hline 13 & $3 \times 106$ & 11602 & 3622 \\
\hline
\end{tabular}

Table 2: Generation cost of reactive power by capacitor bank

\begin{tabular}{|c|c|}
\hline Generation Cost $\frac{\$}{M V A r . h}$ & Capacitor Banks \\
\hline $0.13 \times Q_{C 10}$ & 10 \\
\hline $0.13 \times Q_{C 24}$ & 24 \\
\hline
\end{tabular}




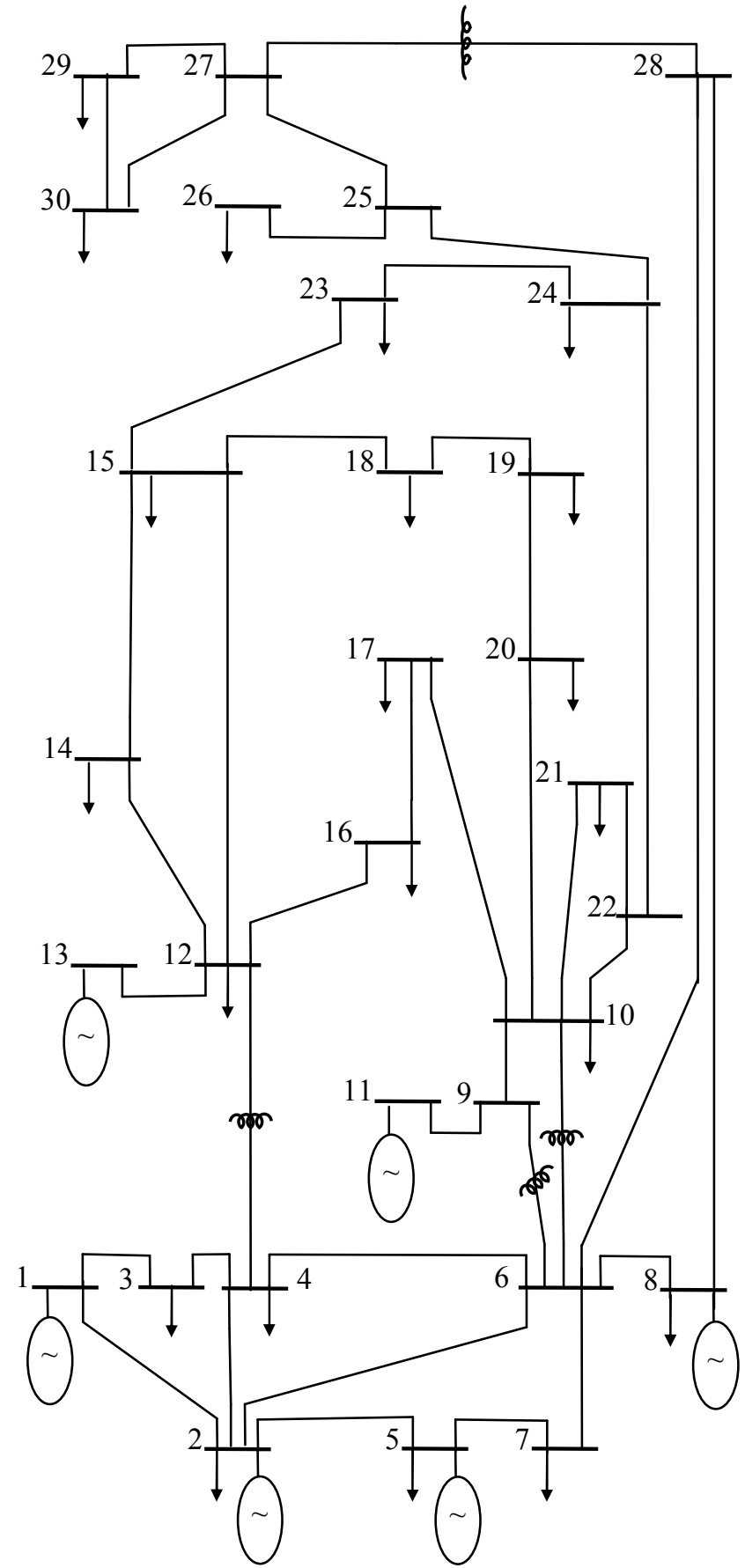

Fig. 2. Modified IEEE 30-bus test system

Table 3. Opportunities cost for reactive power generation

\begin{tabular}{|c|c|c|c|}
\hline $\begin{array}{c}\text { Generator } \\
\text { Bus No. }\end{array}$ & $\begin{array}{c}\$ \\
M V A r . h\end{array}$ & $\begin{array}{c}\text { Generator } \\
\text { Bus No. }\end{array}$ & $\frac{\$}{M V A r . h}$ \\
\hline 1 & 37.50 & 8 & 32.50 \\
\hline 2 & 30.00 & 11 & 16.00 \\
\hline 5 & 53.33 & 13 & 30.00 \\
\hline
\end{tabular}

According to Eq.8 to Eq. 17, the contribution of generators on the transmission lines can be calculated. Obtained results are shown in Table 4.
Table 4: The contribution rate of resources on transmission lines

\begin{tabular}{|c|c|c|c|}
\hline $\begin{array}{l}\text { Line } \\
\text { No. }\end{array}$ & $\begin{array}{c}\text { Generator } \\
\text { Zone }\end{array}$ & $\begin{array}{l}\text { Contributions } \\
\text { at the beginning } \\
\text { of the line }\end{array}$ & $\begin{array}{l}\text { Contributions } \\
\text { in end } \\
\text { of the line }\end{array}$ \\
\hline 1 & 5 & 0.003 & 0 \\
\hline 1 & 7 & 0.002 & 0 \\
\hline 2 & 5 & 0.092 & 0 \\
\hline 2 & 7 & 0.053 & 0 \\
\hline 3 & 5 & 0.783 & 0.583 \\
\hline 3 & 7 & 0.454 & 0.337 \\
\hline 5 & 5 & 2.861 & 1.907 \\
\hline 5 & 7 & 1.658 & 1.105 \\
\hline 6 & 5 & 0.37 & 0.248 \\
\hline 6 & 7 & 0.214 & 0.144 \\
\hline 7 & 5 & 1.761 & 1.497 \\
\hline 7 & 7 & 1.021 & 0.867 \\
\hline 9 & 3 & 2.227 & 2.083 \\
\hline 10 & 5 & 3.384 & 2.866 \\
\hline 12 & 5 & 5.164 & 4.643 \\
\hline 13 & 5 & 3.852 & 0.364 \\
\hline 13 & 7 & 5.315 & 4.642 \\
\hline 16 & 5 & 16.072 & 14.677 \\
\hline 17 & 5 & 22.698 & 21.237 \\
\hline 24 & 6 & 8.697 & 8.193 \\
\hline 25 & 6 & 4.236 & 4.103 \\
\hline 29 & 6 & 2.303 & 2.267 \\
\hline 39 & 6 & 0.355 & 0.284 \\
\hline 41 & 6 & 0.128 & 0.114 \\
\hline
\end{tabular}

\section{CONCLUSION}

- Obtained results shows that the proposed algorithm is suitable and accurate enough for determining the exact contribution rate of generators and loads in the transmission lines.

- The performance of the proposed algorithm for determining the contribution and participation generators and loads rate on the losses of reactive power in generators is considerable.

- According to the results of the simulation, the main differences between the proposed method with other conventional methods for determining the cost of production and transport sectors in the reactive power support, compatibility with the model used in power flow to determine the possible participation reactive power transmission lines in the calculations has provided precisely.

- The proposed method doesn't need to define virtual nodes. The formulation of a branch rather than a node formulation is used and thus can determine the contribution of generators in parallel components is provided.

- Allocating costs in the generation system are calculated using the proposed method obtains the contribution rate of each generators at the load buses. Using the achieved results in each 
of the zones (resources and loads) and the contribution rate of each customer on the transmission lines.

\section{REFERENCES}

[1] G.M.Huang,H.Zhang, "Pricing of Generators' Reactive Power Delivery and Voltage Control in the Unbundled Environment,". Power Engineering Society Summer Meeting, IEEE, pp. 2121 - 2126 vol. 4, 2000.

[2] Y. Dai, X.D. Liu, Y. X. Ni, F. S. Wen, Z. X. Han, C. M. Shen, and F. F. Wu, "A cost allocation method for reactive power service based on power flow tracing", Electric Power Systems Research, vol. 64, pp. 59-65, 2003.

[3] Deksnys R, Staniulis R. "Pricing of reactive power services", Oil Shale Estonian Acad. Publ, pp.363-376, 2007.

[4] Fred C. Schweppe, Michael C. Caramanis, Richard D. Tabors and Roger E. Bohn, "Spot pricing of electricity", Kluwer Academic Publishers, Boston, MA,1988.
[5] M. L. Baughman, S. N. Siddiqi, and J. W. Zarnikau, "Advanced pricing in electrical systems. Part I: Theory," IEEE Trans. Power Systems, vol. 12, no. 1, pp. 489-495, 1997.

[6] M.L. Baughman, S.N Sedighi, "Real Time Pricing of Reactive Power: Theory and Case Study Result", IEEE Trans. Power Syst., 6(1), pp. 23-29, 1991.

[7] J. W. Lamont and J. Fu, "Cost analysis of reactive power support," IEEE Transactions on Power Systems, vol. 14, no. 3, pp. 890-898, Aug. 1999.

[8] E.L.Silva, J.C.O. Mello. "Practical Cost-Based Approach for the Voltage Ancillary Service," IEEE Transactions on Power Systems, Vol.17, No.4, Nov.2001. 